\title{
Review on Space Robotics: Towards Top-Level Science through Space Exploration
}

\author{
Yang Gao', Steve Chien² \\ ${ }^{1}$ Surrey Technology for Autonomous systems and Robotics (STAR) Lab, Surrey Space Centre, \\ University of Surrey, UK \\ 2 Jet Propulsion Laboratory (JPL), California Institute of Technology, USA
}

\begin{abstract}
Robotics and autonomous systems have been instrumental to space exploration in enabling breakthrough science as well as fulfilling human curiosity and ambition to conquer new worlds. This paper provides an overview of space robotics as a rapidly emerging field, covering basic concepts, definitions, historical context and evolution. It further presents the technical roadmap of the field for the coming decades, taking into account major challenges and priorities recognized by the international space community.
\end{abstract}

Space robotics represents several key enablers to a wide range of future robotic and crewed space missions as well as opportunities for knowledge and technology transfer to many terrestrial sectors. In the greater humanitarian context, space robotics inspires both current and future generations to exploration and critical study of Science, Technology, Engineering, and Mathematics (STEM).

\section{Introduction}

Space exploration of our solar system and distant galaxies in the furthest reaches of the Universe is important to top-level science and the answers to many fundamental scientific questions including formation of the Universe, the origin of Earth, Evolution of life, and the Existence of life beyond the Earth. Space robotics plays a critical role in the current and future space exploration missions, and enables mission-defined machines that are capable of surviving in the space environment, and performing exploration, assembly, construction, maintenance, or servicing tasks. Modern space robotics represents a multi-disciplinary emerging field that builds on as well as contributes to knowledge of the space engineering, terrestrial robotics, and computer science as well as related specialties such as materials and mechanisms [1].

Space Robotics is important to human's overall ability to explore or operate in space, by providing greater access beyond human spaceflight limitations in the harsh environment of space and by providing greater operational handling that extends astronauts' capabilities. Autonomous systems are capable of reducing the cognitive load on humans given the abundance of information that has to be reasoned upon in a timely fashion, hence are critical for 
improving human and systems' safety. Robotics can also enable the deployment and operation of multiple assets without the same order of magnitude increase in ground support. Given the potential reduction to the cost and risk of spaceflight both crewed and robotic, space robotics and autonomous systems are deemed relevant across all mission phases such as development, flight system production, launch and operation.

Space robotics covers all types of robotics for the exploration of a planet surface as well as robotics used in orbit around the bodies and the sensors needed by the platform for navigation or control. Orbital robots can be envisaged for repairing satellites, assembling large space telescopes, capturing and returning asteroids, or deploying assets for scientific investigations, etc. Planetary robots play a key role in the surveying, observation, extraction, close examination of extra-terrestrial surfaces (including natural phenomena, terrain composition and resources), constructing infrastructures on a planetary surface for subsequent human arrival, or mining planetary resources, etc.

Two attributes are often deemed essential for a spacecraft to be classified as a space robot, namely locomotion ${ }^{1}$ and autonomy. Depending on its application (either orbital or planetary), a space robot is designed to possess locomotion (or mobility) to manipulate, grip, rove, drill and/or sample. Driven similarly by the nature of the mission and distance from the Earth, the robot is expected to possess varying level of autonomy, ranging from tele-operation by human to fully autonomous operation by the robots themselves ${ }^{2}$. Depending on the level of autonomy, a space robot can act as 1) a robotic agent (or human proxy) in space to perform various tasks using tele-operation up to semi-autonomous operation, or 2) a robotic assistant that can help human astronauts to perform tasks quickly and safely, with higher quality and cost efficiency using semi to fully autonomous operation, or 3) a robotic explorer that is capable of exploring unknown territory in space using fully autonomous operation [3].

In this article we survey past robotic spacecraft missions, current and planned space robotic missions, as well as describe some developmental work targeting future mission concepts. Because of the breadth and depth of the field, we acknowledge that this cannot be a comprehensive technical survey, it is rather intended to provide to the reader a flavour of this diverse and rapidly evolving field. We acknowledge prior surveys by Yoshida [31] in 2009 and Flores-Abad et al. in 2014 that focuses on on-orbit robotic servicing [32]. Additionally, for a more technically detailed coverage of space robotics we refer the reader to [33, 34]

\footnotetext{
${ }^{1}$ Noting this paper does not consider regular orbiting satellite or flyby spacecraft that only have mobility in their orbital trajectory. Additionally, while these spacecraft are technically "robotic" they typically do not have intimate, unpredictable, interactions with their environment more typical of the "robotics field, such as driving mobility, sampling, manipulation or assembly, or atmospheric interactions as with an airplane, helicopter, or aerobot.

${ }^{2}$ Level of autonomy onboard spacecraft defined by European Cooperation for Space Standardization (ECSS) [4]:

Level E1: execution mainly under real-time ground control, i.e. remote or tele-operation.

Level E2: execution of pre-planned mission operations onboard, i.e. automatic operation.

Level E3: execution of adaptive mission operations onboard, i.e. semi-autonomous operation.

Level E4: execution of goal-oriented mission operations onboard, i.e. fully autonomous operation.
} 


\section{History \& Evolution of Space Robotics}

\subsection{Past and Current Space Exploration using Robots}

Outer space has provided real, new exploration frontiers for mankind since the 1950s. With the capability and the irresistible attraction to go beyond our planet Earth, minimizing the impact of mankind on other extra-terrestrial bodies (be it a planet, a moon, a comet or an asteroid) is paramount. The onset of space exploration in the late 1950s to early 1960s focused on sending humans into the Earth orbit and the Moon as a result of the space race between the USSR and USA. In parallel to the expensive development of crewed space programs, the use of cheaper robotic proxies was critical to understand the space environment where the astronauts would be operating as well as to further explore our solar system. Across the existing robotic missions, a range of mobility or locomotion systems has played a significant role, including the surface rovers, robotic arms or manipulators, subsurface samplers and drills.

For example, the first genuine robotic locomotion system successfully operated on an extraterrestrial body was a scoop (i.e., a manipulation cum sampling device) onboard the Surveyor 3 lander launched in 1967 to the Moon. Following that, Luna 16 succeeded with the first planetary robotic arm-mounted drill in 1970, and Luna 17 succeeded with the first planetary rover called Lunokhod 1 in 1970. These "firsts" led to incredible mission successes and science discoveries as a result of unabated and relentless launch attempts during the space race between the superpowers [3].

Table 1 summarizes the missions and robots successfully flown on Earth orbit, the Moon, Mars, and small bodies as of year 2017. Within the orbital missions, robotic arms have been the major mechanism for extended mobility. For the planetary case, most existing missions have utilized either wheeled rovers or stationary landers but equipped with robotic arm, drill or sampler to achieve mobility. Many of the existing missions, particularly for planetary exploration, have achieved remarkable science, e.g. much of what we know about the Moon and Mars has been the direct result of the robotic, in-situ exploration.

Notably, National Aeronautics and Space Administration (NASA) has been in the frontier of Mars science through a series of successful planetary rover missions, i.e. MPF, MER and MSL as introduced in Table 1. Instrumentation carried by the NASA Mars rovers has been substantially increasing with time. As a reference point, the MPF rover "Sojourner" was a relatively small, limited lifetime mobile robot, yet it's key discoveries in geology, likelihood of prior water on Mars, magnetic properties of Martian dust, and current Mars climate rewrote our understanding of Mars [5]. The two identical MER rovers were significantly larger and hence could carry a much more capable science payload including enhanced remote sensing, and more advanced robotic arm carrying instruments for close-in/surface measurement including the Rock Abrasion Tool (RAT), Microscopic Imager, Alpha Proton X-Ray Spectrometer (APXS) and Mossbauer Spectrometer. The rovers also had significantly more advanced mobility and navigation capabilities that have enabled one rover called "Opportunity" to travel over $44 \mathrm{~km}$ in over 4700 sols (i.e. Martian days) as of 2017. The MER rovers achieved even more impressive 
science ranging including geology, atmospheric science, and much more [6-8]. The MSL rover called "Curiosity" is the largest among the three missions and more capable, with next generation instruments to study geology, atmosphere, environmental conditions, and potential biosignatures. From a robotic perspective, Curiosity has a number of instruments that use the robotic arm to take close-in measurements, namely Mars Hand Lens Imager (MAHLI), Alpha Particle X-ray Spectrometer (APXS), as well as sample acquisition analysis (SAM) [9].

Another notable mission is the Japanese Hayabusa robotic mission that studied and sampled the Near Earth Asteroid Itokawa in 2005 and returned these samples to Earth in 2010. The Hayabusa mission achieved considerable science with a special issue in Science on Itokawa study [35] and a subsequent special issue in Science detailing the science from the returned sample [36].

As an alternate data point, the European Space Agency (ESA)'s Rosetta mission made an extremely bold attempt for a controlled landing on a comet nucleus. The Rosetta lander called "Philae" (Figure 1) had a number of remote sensing and in-situ instruments for compositional/gas analysis (e.g. COSAC, Ptolemy), as well as drilling and sample retrieval (i.e. SD2) and surface measurement (i.e. SESAME). Unfortunately the lander bounced and its subsequently canted resting location prevented application of the arm, sampler, and drill and limited Philae's measurements and lifetime. Despite these challenges, Philae has made numerous scientific achievements including the discovery of organic molecules on the nucleus of $67 \mathrm{P} /$ Churyumov-Gerasimenko [10,11].

\subsection{Future Space Robotic Missions}

\subsubsection{Mid-Term Planned Missions}

Table 3 lists a number of upcoming robotic missions planned by various international space agencies in the medium term. It is evident that what was historically the domain of relatively few nations/organizations now includes a much greater rate of launches and diversity of players. Space faring nations like China and India become more active in promoting robotic missions targeting first the Moon as a testbed. NASA and ESA have their focus on Mars and small bodies, who are also ahead of the game in advancing space robotics to tackle sample return missions.

\subsubsection{Orbital Robotic Missions}

There are quite a number of on-orbit applications requiring advanced robotics capabilities, which are envisaged to take place in the 2025-2035 timeframe. The operators for these missions may range from space administrations to national governments to businesses. The following mission foci are envisaged: space debris removal, rescue mission, planned orbit raising, inspection/support to deployment, deployment/assembly aid, repair, refuelling and orbit maintenance, mission evolution/adaptation, lifetime extension, and re/de-orbiting. The International Space Station (ISS) continues to represent an excellent opportunity for scientific experiments to be conducted in space, amid the unique characteristics, constraints and 
pressures that environment brings. China is also actively developing its own space station programme that will be gradually established in the next decade, providing a new mega space platform for robotic solutions. These orbital robotic missions can directly and indirectly support scientific exploration from Earth orbits.

\subsubsection{Planetary Robotic Missions}

Newly planned planetary missions typically aim to deliver more exciting, ambitious scientific goals, building on the results gained from past missions to the Moon, Mars and small bodies. In particular, missions planned by NASA and ESA in the medium term will demonstrate advanced science and robotic technologies compared to their past missions, hence they are further described as follows.

\section{NASA's Osiris-Rex Mission}

Osiris-Rex (Figure 2) was launched in 2016 and will arrive at the Near Earth carbonaceous asteroid 101955 Bennu in 2018. It will map the target for 500 days, culminate in approach and capture a small sample $(<2 \mathrm{~kg})$ to return to the Earth in 2023. Its Touch and Go Sampling Acquisition Mechanism (TAGSAM) uses a sampler head on the end of a robotic arm. When the sample head detects impact, it uses a nitrogen system to acquire a sample. TAGSAM can be used to attempt up to 3 times to acquire a sample. When the spacecraft returns to Earth in 2023, it will use a Sample Return Capsule (Stardust heritage) with re-entry heat shield and parachute to land the sample.

\section{NASA's Insight Mission}

Insight (Figure 3) is a Mars lander that is scheduled for launch and landing on the surface of Mars in 2018. Insight uses many of the same concepts as the prior Phoenix lander mission but uses different instruments to study the Martian interior. The mission uses the Instrument Deployment Arm and Instrument Deployment Camera to deploy two instruments: 1) the Seismic Experiment for Interior Structure (led by CNES, the French National Space Agency), a seismographic instrument used to study the Martian interior and seismic activity; 2) the Heat Flow and Physical Properties Probe (led by DLR, the German National Space Agency), a self burrowing mole that penetrates up to $5 \mathrm{~m}$ below the planetary surface to measure heat escaping from the Martian Interior [12].

\section{NASA's Mars 2020}

The Mars 2020 is US' next rover to Mars and shares considerable heritage with the MSL rover but carries entirely new instruments. The mission will use the Skycrane deployment method (Figure 4) which employs a rocket powered hovering carrier to lower the rover the surface of Mars with a tether. However it enhances the delivery method with Terrain Relative Navigation to enable the system to avoid hazardous terrain in selecting a location to lower the rover. Another significant improvement is that the rover will carry a drill that is capable of coring and caching samples for potential future retrieval to return to Earth. The new rover will also have increased autonomy: including (A) an onboard scheduler to better utilize available time, energy, and data volume [13]; and (B) the ability to autonomously target instruments such as SUPERCAM based 
on scientist provided criteria which is an evolution of the AEGIS system currently on MER [14] and MSL [15].

\section{ESA's ExoMars 2020}

Presently ExoMars (Figure 5) is the only European funded mission to make substantial use of robotics in the form of an autonomous rover, an automated exobiology laboratory and robotised drilling system, due to be launched in 2020 to complement the ExoMars Phase 1 launched in March 2016. Data from the novel suite of instruments on-board the ExoMars rover will help conduct accurate visual and spectral characterisation of the surface of Mars, ranging from panoramic (metre) scales and smaller (sub-millimetre) studies to the molecular identification of organic compounds. The surface study is complemented by electromagnetic and neutron subsurface investigations, which will further help understand the depositional environment (e.g. sedimentary, volcanic, Aeolian). The unique contribution on exobiology from ESA's Mars robotic mission constitutes a step forward in the search for traces of past or present signatures of life on Mars.

\section{ESA-Roscosmos' Phobos Sample Return}

Another robotic mission in study is PHOOTPRINT (Figure 6), which aims at the return of surface samples from Phobos (Mars' Moon). The mission would make use of robotic elements to sample the surface in low gravity. The mission has been initially assessed in two ESA concurrent design facility (CDF) studies, one industrial study and more recently, under the assumption it could become a joint mission with Roscosmos (Russian Space Agency) by a further CDF study. The mission would need the relevant technologies by approximately 2022.

\subsubsection{Long-Term Mission Concepts}

To meet the long-term need for exploration and science, a variety of robotic mission concepts have been proposed and studied by the international space community encompassing efforts from both academia and industry. Table 4 attempts to summarize these ideas in an organized manner without having to create an exhaustive list.

\subsection{Evolution of Space Robotics}

The new generation of space exploration has travelled further into the solar system to tackle more ambitious scientific and exploration goals. Hence it is anticipated to require more capable space robots with diversified locomotion (Table 5) and increased level of autonomy (see Figure 7). Most existing, successfully flown space robots are considered robotic agents that act as human proxies in space. As time progresses, future space missions with increasingly challenging goals will require higher level of autonomy onboard the robots, leading to an evolution towards robotic explorers and robotic assistants.

\subsubsection{Diversified Mobility and Access}

Despite successful exploration performed to date, space robotic systems have literally only scratched the surface. To further advance our knowledge of Earth and other destinations, a 
cornucopia of robotic mobility solution have been proposed by the space community to explore the vast swathes of unexplored landscapes. The exciting new work underway is intended to provide access to more extreme terrain, caves, and aerial exploration of extra-terrestrial surfaces or tackle challenging task in orbit. Table 4 gives an organized view and summary of many proposed ideas up to date, examples from which are further described in Table 6 based on a number of NASA funded studies.

A more comprehensive and system-level mobility concept is humanoid robotics, particularly in the context of human exploration space missions and human-robot interaction. Extremely prominent in this area is NASA's Robonaut program which has been used onboard the ISS as well as the mobile Robonaut "Centaur" in the human-robot "Desert Rats" demonstrations [37] which has also included the ATHLETE non-humanoid limbed robot [38]. Other humanoid robots include DLR's Justin platform [39].

\subsubsection{Increased Level of Autonomy}

Increasing robotic autonomy enables humans interact with or utilize robots at a greater level - as assistants/peers in mixed human-robot teams, or goal-oriented fully autonomous explorer. Planning, scheduling, and resource management enable robotic agents to manage their own actions within resource limitations. Robust task execution systems allow for autonomous robots to persist in uncertain execution environments. Navigation, mode and state estimation and situational awareness capabilities, also called integrated vehicle health management and prognostics enable autonomous robots to track their own state as well as their state within their locale and immediate environment to operate appropriately. These technologies together enable space robots to have increased survivability, increased ability to achieve their desired missions, and more effectively achieve science.

Many R\&D efforts have focused on increasing the efficiency of traditional science measurements using new forms of closed-loop science [21], scientific goal oriented planning [22], and reconfigurable autonomous onboard control [23]. Spacecraft applications already flown on real-world missions include tracking dust devils at Mars [24], retargeting of Mars rover measurements for MER [14] and MSL [15], monitoring of active volcanism [25], cryosphere [26], and flooding [27] from orbit [28]. Future proposed applications include detection and tracking of plumes [29] or surface volatiles at primitive bodies [21].

It is worth noting that advancement in general Al techniques (e.g. machine learning and adaptation) is relevant for improving autonomous functions of space robots in many areas. For example, machine learning is often applied to sensing, perception (e.g. machine vision) tasks. It has also been applied to locomotion such as in improvement of locomotion strategies or policies and navigation. System wide autonomy, planning, scheduling and resource allocation are also areas of continuing work for machine learning. In human robot interaction, learning for adaptation to individual users or specific tasks is an area of active work. And in multi-agent systems, coordination and control as well as data assimilation are all viable applications for machine learning. 


\section{Technical Demands \& Challenges}

The current desire to go and explore space is as strong as ever. Past space powers have been gradually joined by a flurry of new nations eager to test and demonstrate their technologies and contribute to an increasing body of knowledge. Commercial endeavours also have eyes on space and actively promote the Moon and Mars as possible destinations for long-term human presence or habitation. Shall the future exploration missions be crewed or robotic, space robots are always desired to deliver the robotic "avatars" and perform in situ tasks to proxy, assist or explore through their "eyes", "ears", "noses" and "hands" [3].

In particular, the technical goals of robotics are to extend human's reach or access into space, expand our abilities to manipulate assets and resources, prepare them for human arrival, support human crews in their space operations, support the assets they leave behind, and enhance efficiencies of mission operations across the board. Advances in robotic sensing and perception, mobility and manipulation, rendezvous and docking, onboard and ground-based autonomous capabilities, and human-robot integration will drive these goals.

NASA in its latest 2015's technology roadmap has identified several robotics areas needed by 2035 [2]. Similarly, ESA has been developing technology roadmaps in space robotics through various European Commission funded projects such as PERASPERA and SpacePlan2020. Other space faring nations like Russia, China, India and Japan have also announced their individual plans on future missions involving space robotics. Besides difference in mission timetable by different space players, there are quite a number of technological needs or challenges in robotics that are widely acknowledged by the international space community (see Table 7).

\section{New Opportunities}

\subsection{Commercial Entry into Space Robotics}

The competitive landscape of space robotics is changing. Traditionally national entities (e.g. NASA, Roscosmos, ESA, CNSA, and JAXA) were the principal entities in space robotics. However more recently, commercial enterprises have declared their intent and are entering the area. Commercial enterprises are investigating and developing the means to exploit the resources in the Moon and Asteroids. Moon Express, Deep Space Industries, and Planetary Resources all are working towards the long-term goal of exploiting key elements in the Moon and beyond. In the near-term, exploitation of resources beyond Earth could include waterbearing substances to enable in-situ production of rocket fuels (e.g. at the Moon, or at Mars for a return vehicle). In the more distant future, the mining of Helium-3 from the Moon and elsewhere could provide valuable fuel for fusion reactors. Finally, rare metals such as iron, nickel, cobalt, platinum and titanium can be found in many extra-terrestrial bodies. As a nearer term goal, some of these teams are competing for the Google Lunar X prize worth \$30M for operating a rover on the lunar surface. 


\subsection{Knowledge/Technology Transfer to Non-Space Sectors}

Exploration and Robotics is an area of the space industry that is driven heavily by technology and which faces huge challenges to achieve the mission science goals. It is mainly concerned with upstream activities with very little direct downstream benefits to the space industry. It does however have excellent potential for spin along activities allowing the spinning in of terrestrial technologies from other sectors as well as then spinning out the resulting technology advances. Early findings have revealed that current advances being made in R\&D projects on space robotics could have significant knock-on effects in the many sectors including:

- Nuclear facility decommissioning: for post operational clear-out, initial decommissioning, interim decommissioning and final demolition.

- Health \& care: for robotic surgery, diagnostics, independent living, nursing systems, prosthetics, and analysis and therapy.

- Emergency services: for improved responsiveness, reduced risk to life, and more efficient deployment.

- Deep mining: for exploration, excavation, refinement, in wind energy for turbine inspection \& maintenance.

- Seabed robotics: for exploration and exploitation of oil, gas and mineral resources on the ocean floor.

- Water industry: for asset inspection, maintenance and health condition monitoring.

- Agriculture industry: for crop inspection and precision farming.

The markets associated with each of these sectors are expected to undergo huge growth in the coming years, and the adoption and insertion of robotics-based products and services into these applications is expected to deliver economic benefits of at least $\$ 1.9$ trillion by 2025 [30].

\section{Conclusions}

Robotics has demonstrated novel access capabilities for humans to extend their reach in space. Past robotic missions have enabled unique science increasing our knowledge in a wide range of science disciplines. Future robotics missions will continue to change the way space is explored in even more fundamental ways, enabling exploration more frequently, at reduced cost, and ever more challenging and dynamic environments. These missions will both continue our robotic exploration beyond Earth but also play a key role in furthering human exploration beyond Earth.

\section{Acknowledgements}

The authors of the paper would like to thank the UK-RAS Network and various space agencies and funding bodies like NASA, ESA and industrial companies who have sponsored and/or developed robotic technologies mentioned in the paper. Portions of this research were carried out by the JPL, California Institute of Technology, under a contract with the National Aeronautics and Space Administration. The authors also thank the reviewers for many helpful comments to improve the article. 


\section{References}

[1] Y. Gao et. al., UK-RAS White Paper on Space Robotics \& Autonomous Systems: Widening the horizon of space exploration, (2016). http://hamlyn.doc.ic.ac.uk/ukras/sites/default/files/UK_RAS_wp_space.pdf

[2] NASA Technology Roadmaps - TA 4: Robotics and Autonomous Systems, (2015).

[3] Y. Gao, (Ed.) Contemporary Planetary Robotics - An Approach to Autonomous Systems, pp. 1-450, Wiley-VCH, ISBN-13: 978-3527413256, (2016).

[4] Space Engineering- Space Segment Operability (ECSS-E-70-11A), European Cooperation for Space Standardization, (2005).

[5] Reports on Mars Pathfinder Mission, Science, Vol 278, Issue 5344, 05 December 1997.

[6] Crisp JA, Adler M, Matijevic JR, Squyres SW, Arvidson RE, Kass DM. Mars exploration rover mission. Journal of Geophysical Research: Planets, 108(E12), (2003).

[7] Squyres SW, Arvidson RE, Bollen D, Bell JF, Brueckner J, Cabrol NA, Calvin WM, Carr MH, Christensen PR, Clark BC, Crumpler L. Overview of the opportunity mars exploration rover mission to meridiani planum: Eagle crater to purgatory ripple. Journal of Geophysical Research: Planets, 111(E12), (2006).

[8] Arvidson RE, Squyres SW, Anderson RC, Bell JF, Blaney D, Brueckner J, Cabrol NA, Calvin WM, Carr MH, Christensen PR, Clark BC. Overview of the spirit Mars exploration rover mission to Gusev Crater: Landing site to Backstay Rock in the Columbia Hills. Journal of Geophysical Research: Planets, 111(E2), (2006).

[9] Grotzinger JP, Crisp J, Vasavada AR, Anderson RC, Baker CJ, Barry R, Blake DF, Conrad P, Edgett KS, Ferdowski B, Gellert R. Mars Science Laboratory mission and science investigation. Space science reviews, 170(1-4), 5-6, (2012).

[10] Goesmann F, Rosenbauer H, Bredehöft JH, Cabane M, Ehrenfreund P, Gautier T, Giri C, Krüger H, Le Roy L, MacDermott AJ, McKenna-Lawlor S. Organic compounds on comet 67P/Churyumov-Gerasimenko revealed by COSAC mass spectrometry. Science, 349(6247):aab0689, (2015).

[11] Wright IP, Sheridan S, Barber SJ, Morgan GH, Andrews DJ, Morse AD. CHO-bearing organic compounds at the surface of 67P/Churyumov-Gerasimenko revealed by Ptolemy. Science, 349(6247):aab0673, (2015).

[12] Banerdt WB, Smrekar S, Lognonné P, Spohn T, Asmar SW, Banfield D, Boschi L, Christensen U, Dehant V, Folkner W, Giardini D. InSight: a discovery mission to explore the interior of Mars, Proceeding of Lunar and Planetary Science Conference, Vol. 44, p. 1915, (2013).

[13] G. Rabideau and E. Benowitz, "Prototyping an Onboard Scheduler for the Mars 2020 Rover," Proceeding of International Workshop on Planning and Scheduling for Space, Pittsburgh, PA, 2017.

[14] Estlin TA, Bornstein BJ, Gaines DM, Anderson RC, Thompson DR, Burl M, Castaño R, Judd $\mathrm{M}$. Aegis automated science targeting for the mer opportunity rover. ACM Transactions on Intelligent Systems and Technology (TIST), 3(3):50, (2012).

[15] R. Francis, T. Estlin, G. Doran, S. Johnstone, D. Gaines, V. Verma, M. Burl, J. Frydenvang, S. Montaño, R. C. Wiens, S. Schaffer, O. Gasnault, L. DeFlores, D. Blaney, B. Bornstein, 
AEGIS autonomous targeting for ChemCam on Mars Science Laboratory: Deployment \& results of initial science team use. Science Robotics, to appear, (2017).

[16] NASA/JPL Mars Helicopter, https://www.jpl.nasa.gov/news/news.php?feature=4457, retrieved 17 April 2017.

[17] Braun RD, Wright HS, Croom MA, Levine JS, Spencer DA. Design of the ARES Mars airplane and mission architecture. Journal of Spacecraft and Rockets. 2006 Sep;43(5):1026-34. [18] Hall JL, Kerzhanovich VV, Yavrouian AH, Jones JA, White CV, Dudik BA, Plett GA, Mennella J, Elfes A. An aerobot for global in situ exploration of Titan. Advances in Space Research, 37(11):2108-19, (2006).

[19] Nesnas IA, Matthews JB, Abad-Manterola P, Burdick JW, Edlund JA, Morrison JC, Peters RD, Tanner MM, Miyake RN, Solish BS, Anderson RC. Axel and DuAxel rovers for the sustainable exploration of extreme terrains. Journal of Field Robotics, 29(4):663-85, (2012).

[20] Berisford DF, Leichty J, Klesh A, Hand KP. Remote Under-Ice Roving in Alaska with the Buoyant Rover for Under-Ice Exploration. In AGU Fall Meeting Abstracts 2013 Dec.

[21] S Chien, Agile Science, A New Paradigm for Space Missions, Invited Talk, Flight Software Workshop, Pasadena, CA, USA 2016.

[22] Ceballos A, et al. A goal-oriented autonomous controller for space exploration, Proc. ESA Symposium on Advanced Space Technologies in Robotics \& Automation (ASTRA), (2011).

[23] G. Burroughes and Y. Gao, "Ontology-Based Self-Reconfiguring Guidance, Navigation, and Control for Planetary Rovers". AIAA Journal of Aerospace Information Systems, 2016, doi: 10.2514/1.1010378.

[24] Castano A, Fukunaga A, Biesiadecki J, Neakrase L, Whelley P, Greeley R, Lemmon M, Castano R, Chien S. Automatic detection of dust devils and clouds on Mars. Machine Vision and Applications, 19(5), 467-82, (2008).

[25] Davies AG, Chien S, Baker V, Doggett T, Dohm J, Greeley R, Ip F, Castan R, Cichy B, Rabideau G, Tran D. Monitoring active volcanism with the autonomous sciencecraft experiment on EO-1. Remote Sensing of Environment, 101(4), 427-46, (2006).

[26] T. Doggett, R. Greeley, A. G. Davies, S. Chien, B. Cichy, R. Castano, K. Williams, V. Baker, J. Dohm and F. Ip (2006) Autonomous On-Board Detection of Cryospheric Change, Remote Sensing of Environment, 101(4): 447-, (2006).

[27] Ip F, Dohm JM, Baker VR, Doggett T, Davies AG, Castano R, Chien S, Cichy B, Greeley R, Sherwood R, Tran D. Flood detection and monitoring with the Autonomous Sciencecraft Experiment onboard EO-1. Remote Sensing of Environment, 101(4), 463-81, 2006.

[28] S Chien, R Sherwood, D Tran, B Cichy, G Rabideau, R Castano, A Davies, D Mandl, B Trout, S Shulman, D Boyer. Using autonomy flight software to improve science return on Earth Observing One. Journal of Aerospace Computing, Information, and Communication, 2(4), 196216, (2005).

[29] K. L. Wagstaff, D. R. Thompson, B. D. Bue, and T. J. Fuchs. Autonomous Real-time Detection of Plumes and Jets from Moons and Comets, The Astrophysical Journal, 794(1), doi:10.1088/0004-637X/794/1/43, (2014).

[30] European Commission funded Space Robotics Strategic Research Cluster (SRC) report on knowledge \& technology transfer for space robotics, 2017.

[31] Kazuya Yoshida, "Achievements in Space Robotics", IEEE Robotics \& Automation

Magazine, Vol. 16, No. 4, 2009, pp. 20-28. 
[32] Angel Flores-Abad, Ou Ma, Khanh Pham and Steve Ulrich, "A Review of Robotics Technologies for On-Orbit Services", Progress in Aerospace Science, Vol.68, 2014, pp.1-26.

[33] Kazuya Yoshida, Dragomir Nenchev, Genya Ishigami and Yuichi Tsumaki, Chapter 19 "Space Robotics", The International Handbook of Space Technology, Springer 2014, Editors: Malcolm Macdonald and Viorel Badescu.

[34] Kazuya Yoshida, Brian Wilcox, Gerd Hirzinger and Roberto Lampariello, Chapter 55 "Space Robotics", Springer Handbook of Robotics, 2nd edition, 2016, Editors:

Bruno Siciliano and Oussama Khatib.

[35] Special issue, Science, Vol. 312, Issue 5778, 2006.

[36] Special issue, Science, Vol. 333, Issue 6046, 2011.

[37] Ross A, Kosmo J, Janoiko B. Historical synopses of Desert RATS 1997-2010 and a preview of Desert RATS 2011. Acta Astronautics, 90(2), 182-202, (2013).

[38] Wilcox BH. ATHLETE: A limbed vehicle for solar system exploration, Proceeding of IEEE Aerospace Conference, 1-9, (2012).

[39] Borst C, Wimbock T, Schmidt F, Fuchs M, Brunner B, Zacharias F, Giordano PR, Konietschke R, Sepp W, Fuchs S, Rink C. Rollin'Justin-Mobile platform with variable base, Proceeding IEEE International Conference on Robotics \& Automation, 1597-1598, (2009).

Figure 1: Artistic depiction of Philae lander at landing (courtesy ESA)

Figure 2: Osiris-Rex Spacecraft with TAGSAM robotic sampling arm (Courtesy NASA)

Figure 3: Insight Lander with Robotic Instrument Deployment Arm and Seismic sensor and Heat Flow sensor deployed (Courtesy NASA).

Figure 4: Mars 2020 rover being deployed by Skycrane (Courtesy NASA)

Figure 5: ExoMars 2020 with rover and deep drill assembly (Courtesy ESA)

Figure 6: Phobos sample return mission concept (Courtesy Airbus DS Ltd)

Figure 7: Evolution of space robots in terms of level of autonomy [1]. 
Table 1: Successfully flown robots on Earth orbit, the Moon, Mars, and small bodies as of 2016 [3].

\begin{tabular}{|c|c|c|c|c|c|c|c|}
\hline Launch Year & Mission Name & Country & Target & Rover & Arm & Sampler & Drill \\
\hline 1967 & Surveyor 3 & USA & Moon & & & $x$ & \\
\hline 1970/72/76 & Luna $16 / 20 / 24$ & USSR & Moon & & $x$ & $x$ & $x$ \\
\hline 1970/73 & Luna $17 / 21$ & USSR & Moon & $x$ & & & \\
\hline 1975 & Viking & USA & Mars & & $x$ & $x$ & \\
\hline 1981/2001/08 & Canadarm1/2/Dextre @ ISS & Canada & Earth orbit & & $x$ & & \\
\hline 1993 & Rotex & Germany & Earth Orbit & & $x$ & & \\
\hline 1996 & Mars Pathfinder (MPF) & USA & Mars & $x$ & & & \\
\hline 1997 & ETS-VII & Japan & Earth Orbit & & $x$ & & \\
\hline 2003 & Hayabusa & Japan & Asteroid & & & $x$ & \\
\hline 2003 & $\begin{array}{l}\text { Mars Exploration Rovers } \\
\text { (MER) }\end{array}$ & USA & Mars & $x$ & $x$ & $x$ & \\
\hline 2004 & ROKVISS & Germany & ISS & & $x$ & & \\
\hline 2007 & Orbital Express & USA & Earth Orbit & & $x$ & & \\
\hline 2008 & JEMRMS & Japan & ISS & & $x$ & & \\
\hline 2008 & Phoenix & USA & Mars & & $x$ & $x$ & \\
\hline 1022 & Robonaut & USA & ISS & & $x$ & & \\
\hline 2011 & $\begin{array}{l}\text { Mars Science Laboratory } \\
\text { (MSL) }\end{array}$ & USA & Mars & $x$ & $x$ & $x$ & \\
\hline 2013 & Chang'E 3 & China & Moon & $x$ & & & \\
\hline $\begin{array}{l}2004 \text { (arrived } \\
\text { in } 2014\end{array}$ & Rosetta & Europe & Comet & & $x$ & $x$ & $x$ \\
\hline 2016 & Aolong-1 & China & Earth orbit & & $x$ & & \\
\hline
\end{tabular}


Table 2: Growing science capabilities of NASA's Mars robotic missions as exemplified by each generation of Mars Rover.

\begin{tabular}{|c|c|c|c|c|c|c|}
\hline Mars Rover & Mass & Lifetime & $\begin{array}{l}\text { Distance } \\
\text { Travelled } \\
\text { (as of April } \\
\text { 2017) }\end{array}$ & $\begin{array}{l}\text { Maximum } \\
\text { Traverse } \\
\text { Speed }\end{array}$ & $\begin{array}{l}\text { Science } \\
\text { Payload } \\
\text { Mass }\end{array}$ & $\begin{array}{l}\text { Science } \\
\text { Results } \\
\text { Reported }\end{array}$ \\
\hline $\begin{array}{l}\text { MPF's } \\
\text { Sojourner }\end{array}$ & $10 \mathrm{~kg}$ & 83 sols & $0.1 \mathrm{~km}$ & $0.6 \mathrm{~cm} / \mathrm{s}$ & $<1 \mathrm{~kg}$ & [5] \\
\hline $\begin{array}{l}\text { MER's } \\
\text { Opportunity }\end{array}$ & $185 \mathrm{~kg}$ & 4500 sols* & $>44 \mathrm{~km}$ & $1 \mathrm{~cm} / \mathrm{s}$ & $6 \mathrm{~kg}$ & {$[6,7,8]$} \\
\hline $\begin{array}{l}\text { MSL's } \\
\text { Curiosity }\end{array}$ & $899 \mathrm{~kg}$ & 1667 sols* & $>15.98 \mathrm{~km}$ & $5 \mathrm{~cm} / \mathrm{s}$ & $75 \mathrm{~kg}$ & [9] \\
\hline
\end{tabular}

*Still in operations as of 2017.

Table 3: Medium-term space robotic missions in the pipeline

\begin{tabular}{|c|c|c|c|c|c|c|c|}
\hline $\begin{array}{l}\text { Launch } \\
\text { Year }\end{array}$ & Mission & Country & Target & Rover & Arm & Sampler & Drill \\
\hline 2017 & Chang'E 5 & China & Moon & $x$ & $x$ & $x$ & $x$ \\
\hline 2018 & Chandrayaan 2 & India & Moon & $x$ & & & \\
\hline $\begin{array}{l}2018 \text { (to } \\
\text { arrive) }\end{array}$ & $\begin{array}{l}\text { Osiris-Rex Sample } \\
\text { Return }\end{array}$ & USA & NEA & & $x$ & $x$ & \\
\hline 2018 & Insight & USA & Mars & & $x$ & $x$ & $x$ \\
\hline 2018 & Chang'E 4 & China & Moon (far side) & $x$ & & & \\
\hline 2019 & SLIM & Japan & Moon & $x$ & $x$ & $x$ & $x$ \\
\hline 2020 & Mars 2020 & USA & Mars & & & & \\
\hline 2020 & ExoMars 2020 & Europe & Mars & $x$ & & $x$ & $x$ \\
\hline $2020+$ & Chinese Space Station & China & Earth orbit & & $x$ & & \\
\hline 2025 & Phobos Sample Return & Europe \& Russia & Phobos & & $x$ & $x$ & \\
\hline
\end{tabular}


Table 4: Long-term space robotic mission concepts [3]

\begin{tabular}{lll} 
Destination & Proposed Mission Concepts & Proposed Robotic Locomotion \\
\hline Earth orbit & Space debris removal, On-orbit servicing \& assembly & Arm, Hand/Gripper, Harpoon \\
Moon & Sample return, In-situ resource utilization (ISRU), & Rover, Arm, Sampler, Drill \\
& $\begin{array}{l}\text { exploration of permanently shaded craters, prepare } \\
\text { for manned base }\end{array}$ & \\
Mars & Sample return, ISRU, crewed base & Aeroshell, Airplane, Helicopter, \\
Venus & Exploration & Balloon, Hopper, Swarms \\
Mercury & Exploration & Balloon \\
Asteroid & Sample return, ISRU & Rover \\
Titan & Exploration & Rover, Hopper, Arm, Harpoon \\
& & Aeroshell, Aerobot, Balloon, \\
& & Lake Lander, Submarine, Ship, \\
Europa/Enceladus & Exploration & Cooperative robots \\
Gas giants & Exploration & Subsurface, Submarine, Hopper \\
\hline
\end{tabular}

Table 5: Diversified locomotion for future space robots [3]

\begin{tabular}{ll}
\hline Robotic Platform & Robotic Locomotion \\
\hline Land surface & - Wheeled rover \\
& - Tracked rover \\
& - Legged rover \\
& - Rolling (e.g. ball or sphere) rover \\
& - Hopper \\
& - Hovercraft \\
& - Quadcopter, helicopter, or ornithopter \\
Airborne & - Plane or glider \\
& - Balloon, Montgolfiere, Aerobot \\
& - Drill (e.g. ice drilling or melting, rotary drilling, \\
Subsurface & percussive drilling, dual reciprocating drilling) \\
& - Submarine, submersible \\
Manipulation & - Arm \\
& - Hand, gripper \\
& - Sampler (e.g. corer, scoop)
\end{tabular}


Table 6: Examples of novel robotic locomotion concepts for future space exploration (Courtesy JPL/NASA)

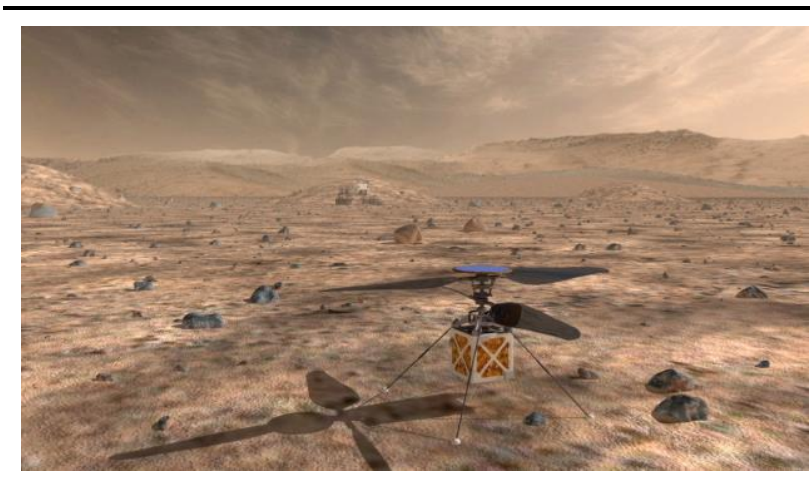

\section{Mars Helicopter [16]}

Mars helicopter is proposed to facilitate surface rover operations. Despite the thin Martian atmosphere, only $0.6 \%$ of the Earth's, the solar powered Mars helicopter at $1 \mathrm{~kg}$ in mass and with a $1.1 \mathrm{~m}$ long rotor, would scout ahead of a surface rover, providing critical imagery to enable the rover to drive up to three times as far per sol.

\section{Mars Airplane [17]}

While the extremely thin Martian atmosphere makes air vehicles challenging, a Mars airplane is proposed as the Preliminary Research Aerodynamic Design to Land on Mars (or Prandtl-m). A Mars airplane could be released as part of the Entry Descent and Landing ballast for a future Mars landed mission to acquire unique airborne imaging of the

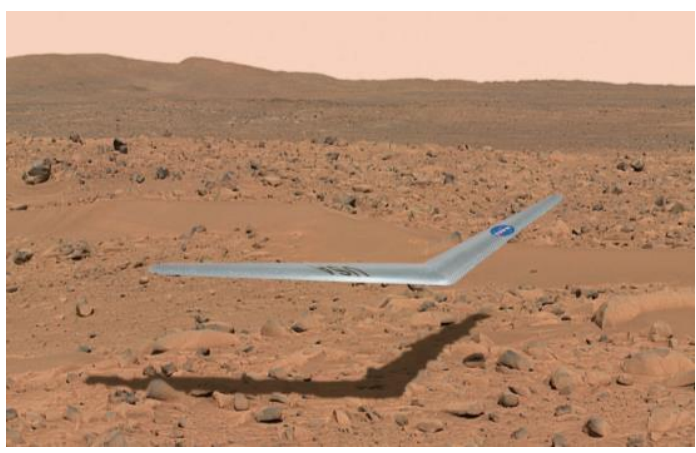
Martian surface.

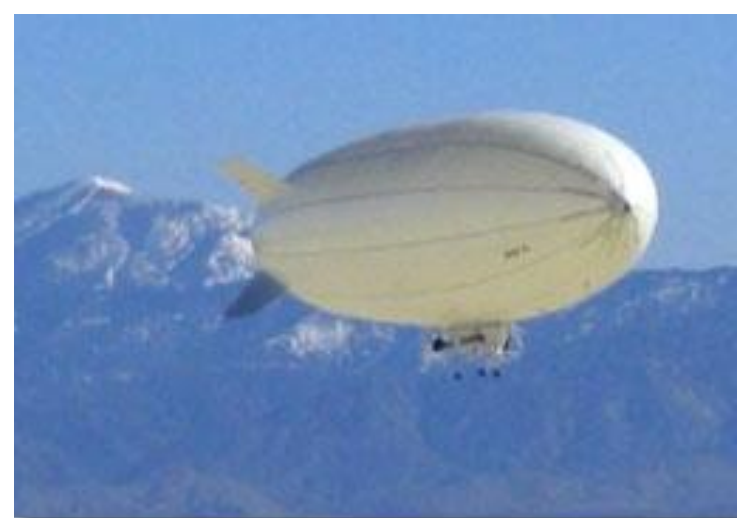

Test flight in the Mojave Desert, CA, USA

\section{Titan Aerobot [18]}

With a dense methane atmosphere providing strong lift and weak gravity, an aerobot is an ideal vehicle to explore Titan, a moon of Saturn. Titan is of great interests to scientists because of its abundant methane as a possible ingredient for life and its liquid methane lakes on the surface. Aerobots and montgolfieres have been proposed and tested to develop technologies for this ambitious robotic mission. 


\section{Mars Dual Axel Rover [19]}

Recent interest in Recurrent Slope Linnae (RSL) as liquids on the surface of Mars has spurred interest in robotic access to extreme slopes in order to study these science phenomena. The axel robot is a single axle with tether designed to rappel down steep slopes. In a dual axel rover configuration, one axel would remain at the top of the slope as an anchor to allow the other axel to rappel down the slope.
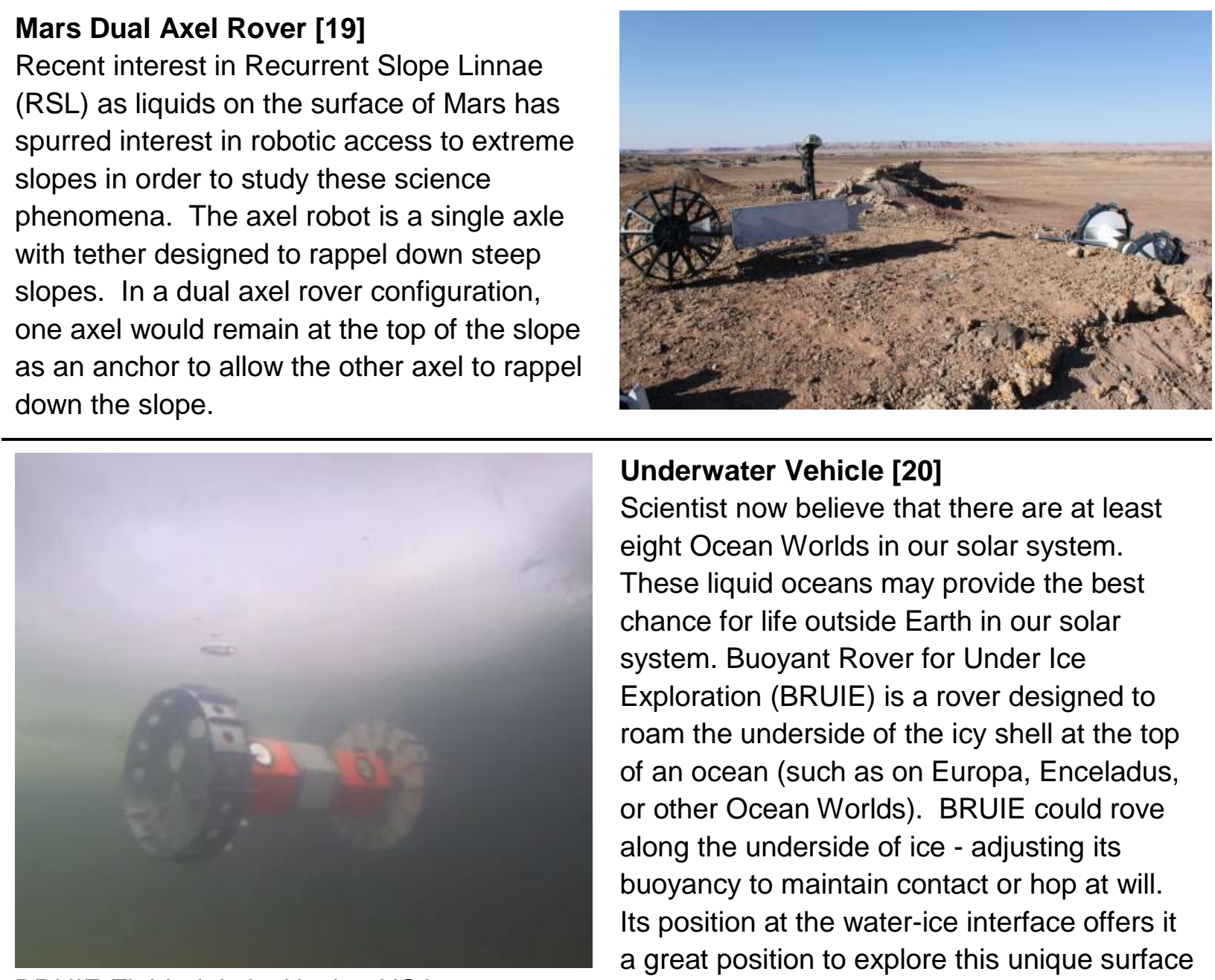

Underwater Vehicle [20]

Scientist now believe that there are at least eight Ocean Worlds in our solar system. These liquid oceans may provide the best chance for life outside Earth in our solar system. Buoyant Rover for Under Ice Exploration (BRUIE) is a rover designed to roam the underside of the icy shell at the top of an ocean (such as on Europa, Enceladus, or other Ocean Worlds). BRUIE could rove along the underside of ice - adjusting its buoyancy to maintain contact or hop at will. Its position at the water-ice interface offers it a great position to explore this unique surface BRUIE Field trials in Alaska, USA where evidence of life may exist.

Table 7: Technological needs and challenges for space robotics in the coming decades.

\begin{tabular}{|c|c|c|c|}
\hline Areas & Goals & $\begin{array}{l}\text { Technological Needs } \\
\text { or Challenges }\end{array}$ & $\begin{array}{l}\text { Relevance to Achieving Top- } \\
\text { Level Science }\end{array}$ \\
\hline $\begin{array}{l}\text { Sensing \& } \\
\text { perception }\end{array}$ & $\begin{array}{l}\text { To provide } \\
\text { situational } \\
\text { awareness for } \\
\text { space robotic } \\
\text { agents, explorers } \\
\text { and assistants. }\end{array}$ & $\begin{array}{l}\text { - New sensors. } \\
\text { - Sensing techniques; } \\
\text { - Algorithms for 3D } \\
\text { perception, state } \\
\text { estimation and data } \\
\text { fusion. } \\
\text { - Onboard data } \\
\text { processing and generic } \\
\text { software framework. }\end{array}$ & $\begin{array}{l}\text { The sensors provide the vast } \\
\text { bulk of the direct science: } \\
\text { - Increases in instruments, } \\
\text { both remote sensing and in- } \\
\text { situ enable more precise } \\
\text { measurements (e.g, spatial, } \\
\text { spectral resolution, while } \\
\text { reducing volume, mass, } \\
\text { power). }\end{array}$ \\
\hline
\end{tabular}




\begin{tabular}{|c|c|c|c|}
\hline & & $\begin{array}{l}\text { - Object, event or activity } \\
\text { recognition. }\end{array}$ & $\begin{array}{l}\text { - New types of instruments } \\
\text { are emerging. Imaging } \\
\text { spectroscopy to determine } \\
\text { composition; Lidar for 3D } \\
\text { mapping; Interferometric } \\
\text { radar for change detection, } \\
\text { structure; Sample } \\
\text { processing for life detection } \\
\text { and astrobiology enable new } \\
\text { measurements for new types } \\
\text { of science. }\end{array}$ \\
\hline $\begin{array}{l}\text { Mobility or } \\
\text { Locomotion }\end{array}$ & $\begin{array}{l}\text { To reach and } \\
\text { operate at sites of } \\
\text { scientific interest } \\
\text { on extra- } \\
\text { terrestrial } \\
\text { surfaces or free } \\
\text { space } \\
\text { environments. }\end{array}$ & $\begin{array}{l}\text { - Mobility on, into, and } \\
\text { above an extra- } \\
\text { terrestrial surface using } \\
\text { locomotion like flying, } \\
\text { walking, climbing, } \\
\text { rappelling, tunnelling, } \\
\text { swimming and sailing. } \\
\text { - Melting through the } \\
\text { kms thick ocean worlds } \\
\text { ice shells of Europa, } \\
\text { Enceladus or Pluto. } \\
\text { - Manipulations to make } \\
\text { intentional changes in } \\
\text { the environment or } \\
\text { objects using } \\
\text { locomotion like placing, } \\
\text { assembling, digging, } \\
\text { trenching, drilling, } \\
\text { sampling, grappling } \\
\text { and berthing. }\end{array}$ & $\begin{array}{l}\text { Locomotion represents the } \\
\text { ability to explore an } \\
\text { environment, such as rovers, } \\
\text { aerobots, and submarines. } \\
\text { Melting through Ocean Worlds } \\
\text { Ice shells enables access } \\
\text { habitable oceans underneath. } \\
\text { Digging, trenching, coring } \\
\text { enables access to materials } \\
\text { without atmospheric } \\
\text { contamination (e.g. Mars } \\
\text { geology) or radiation (e.g. } \\
\text { Europa astrobiology). }\end{array}$ \\
\hline $\begin{array}{l}\text { High-level } \\
\text { autonomy } \\
\text { for system } \\
\text { and } \\
\text { subsystems }\end{array}$ & $\begin{array}{l}\text { To provide robust } \\
\text { and safe } \\
\text { autonomous } \\
\text { navigation, } \\
\text { rendezvous and } \\
\text { docking } \\
\text { capabilities and to } \\
\text { enable extended- } \\
\text { duration } \\
\text { operations } \\
\text { without human }\end{array}$ & $\begin{array}{l}\text { - Guidance, navigation } \\
\text { and control (GNC) } \\
\text { algorithms. } \\
\text { - Docking and capture } \\
\text { mechanisms and } \\
\text { interfaces. } \\
\text { - Planning, scheduling \& } \\
\text { common autonomy } \\
\text { software framework. } \\
\text { - Multi-agent } \\
\text { coordination }\end{array}$ & $\begin{array}{l}\text { - Enhanced GNC means } \\
\text { higher precision navigation } \\
\text { for better science } \\
\text { measurements. Scheduling, } \\
\text { execution, IVHM, enables } \\
\text { more productive science time } \\
\text { for vehicles. } \\
\text { - Automated science analysis } \\
\text { and scheduling enables } \\
\text { closing the loop without } \\
\text { ground in the loop, enabling }\end{array}$ \\
\hline
\end{tabular}




\begin{tabular}{|c|c|c|c|}
\hline & $\begin{array}{l}\text { interventions to } \\
\text { improve overall } \\
\text { performance of } \\
\text { human and } \\
\text { robotic missions. } \\
\text { To enable closed } \\
\text { loop science for } \\
\text { more efficient, } \\
\text { novel science } \\
\text { (e.g., tracking a } \\
\text { dynamic plume at } \\
\text { a comet). }\end{array}$ & $\begin{array}{l}\text { - Reconfigurable and } \\
\text { adjustable autonomy. } \\
\text { - Automated data } \\
\text { analysis for decision } \\
\text { making, FDIR/IVHM } \\
\text { and execution. }\end{array}$ & $\begin{array}{l}\text { more science cycles per } \\
\text { mission (i.e. higher } \\
\text { productivity and unique, } \\
\text { opportunistic science). }\end{array}$ \\
\hline $\begin{array}{l}\text { Human- } \\
\text { robot } \\
\text { interaction }\end{array}$ & $\begin{array}{l}\text { To enable human } \\
\text { to accurately and } \\
\text { rapidly } \\
\text { understand the } \\
\text { state of the robot } \\
\text { in collaboration } \\
\text { and act effectively } \\
\text { and efficiently } \\
\text { towards the goal } \\
\text { state. }\end{array}$ & $\begin{array}{l}\text { - Multi-modal interaction; } \\
\text { Remote and supervised } \\
\text { control; } \\
\text { - Proximate interaction; } \\
\text { - Distributed } \\
\text { collaboration and } \\
\text { coordination; } \\
\text { - Common human- } \\
\text { system interfaces. }\end{array}$ & $\begin{array}{l}\text { Virtual reality and augmented } \\
\text { reality allow more natural } \\
\text { interfaces to analyse vast } \\
\text { acquired data streams. VR } \\
\text { and AR also allow for natural } \\
\text { means of vehicle controlling } \\
\text { such as by reach, touch, and } \\
\text { gesture. }\end{array}$ \\
\hline $\begin{array}{l}\text { System } \\
\text { engineering }\end{array}$ & $\begin{array}{l}\text { To provide a } \\
\text { framework for } \\
\text { understanding } \\
\text { and coordinating } \\
\text { the complex } \\
\text { interactions of } \\
\text { robots and } \\
\text { achieving the } \\
\text { desired system } \\
\text { requirements. }\end{array}$ & $\begin{array}{l}\text { - Modularity, } \\
\text { commonality and } \\
\text { interfaces; } \\
\text { - Verification and } \\
\text { validation of complex } \\
\text { adaptive systems; } \\
\text { - Robot modelling and } \\
\text { simulation; } \\
\text { - Software architectures } \\
\text { and frameworks; } \\
\text { - Safety and trust. }\end{array}$ & $\begin{array}{l}\text { High stakes in billions requires } \\
\text { reliable mission. As systems } \\
\text { become increasingly complex, } \\
\text { being able to characterize } \\
\text { robotic behaviour (especially } \\
\text { for multi vehicle swarms) } \\
\text { becomes increasingly } \\
\text { challenging. }\end{array}$ \\
\hline
\end{tabular}

